\title{
EL GRAN ENIGMA QUE ES EL SER HUMANO PARA SÍ MISMO SE ILUMINA CON LA FIGURA DE JESÚS Entrevista a Alberto Simons Camino, S. J.
}

\author{
Giovani Sandoval Lozano* \\ Universidad Católica Sedes Sapientiae
}

Resumen: Alberto Simons es director del Instituto Fe y Cultura de la Universidad Antonio Ruiz de Montoya, profesor principal de Antropología Filosófica y «Jesús y la religión» en la misma Universidad y profesor principal de Teología en la Pontificia Universidad Católica del Perú. Autor de numerosas investigaciones en torno a la filosofía, teología, religión y cultura, recientemente ha publicado SER HUMANO. Ensayo de Antropología Cristológica (Fondo Editorial PUCP-Fondo Editorial UARM), volumen que está dirigido a un público amplio, aún aquellos que no comparten la fe cristiana pero buscan un mundo más humano.

En esta entrevista Simons nos habla de Jesús como respuesta al misterio del hombre, y nos lleva a reconocer la profundidad e importancia de la

* Giovani Sandoval Lozano tiene estudios concluidos de Maestría en Filosofía por la UNMSM, además de una licenciatura en Filosofía y Religión. Actualmente inicia los estudios de doctorado en Filosofía y realiza un diplomado en Ética y Política en la UARM. Es profesor ordinario en la Universidad Católica Sedes Sapientiae. También desempeña su labor como Administrador, impartiendo la cátedra de Ética para empresarios en IPAE. 
extraordinaria personalidad de Jesús. El amor que vive y dona Jesús, y que no hace distinción alguna, ha hecho que se mueva la razón y voluntad de quienes se relacionaron con Él; en ese sentido, se sabe qué es ser plenamente humano a partir de Jesús. Simons también remarca el hecho de que nuestra vida de fe no consistiría en copiar a Jesús, sino vivir en esta dimensión desde el ámbito y contexto que nos ha tocado vivir en el seguimiento de su forma de vivir. Otros temas que se explican en esta conversación son la inteligencia, libertad y afectividad humana, la solidaridad y la esperanza.

Palabras Clave: Jesús, cristología, teología, religión

Abstract: Alberto Simons is the Instituto Fe y Cultura director at Antonio Ruiz de Montoya University, principal professor of Philosophical Anthropology and «Jesus and religion» at the same university and principal professor of Theology at Pontificia Universidad Católica del Perú. A. Simons has done a lot of research on philosophy, theology, religion and culture. He has recently published HUMAN BEING. Essay on Christological Anthropology (Ser humano. Ensayo de Antropología Cristológica) (Fondo Editorial PUCP-Fondo Editorial UARM), volume addressed to a wide range of people, even to those who don't share the Christian faith but are in search of a more humanistic world.

In this interview, Simons talks about Jesus as a reply to the man's mystery and guides us to the recognition of the profundity and importance of Jesus' extraordinary personality. Love that is lived and given by Jesus without distinction of any kind has moved people's reason and will, especially of those who were related with him. In this sense, it is known what is to be fully human through Jesus. Simons also remarks the fact that our life of faith would not consist in imitating Jesus, but living in this dimension in the domain and context in which we are involved through the continuation 
of his way of living. Intelligence, liberty and human affection, solidarity and hope are other issues that are explained in this conversation.

KeY words: Jesus, Christology, theology, religion

\section{EL HOMBRE ES UN SER EN BUSCA DE SU HUMANIDAD}

Hoy vivimos una época marcada por la exaltación de lo que llama el mundo 'bumanidad', incluso en los círculos llamados académicos. Desde la obra de Nietzsche, Humano demasiado humano, el hombre se ha enaltecido aún más, y lo religioso del hombre se ve disipado por una especie de atmósfera donde lo humano y lo sensible se juntan para formar un hombre ajeno a su dimensión de fe natural. ¿Qué busca, entonces, al enaltecer la humanidad de Jesús en su libro Ser Humano. Ensayo de Antropología Cristológica, (Fondo Editorial de la Universidad Antonio Ruíz de Montoya - Fondo Editorial PUCP, 2011) dadas las circunstancias planteadas?

El motivo es hacer que la figura de Jesús, el Evangelio, sea cercano a nuestras vidas, porque ser cristianos no es creer en unos principios o en unos dogmas, o seguir determinada moral. Lo importante es el seguimiento de Jesús, y aquí reside la hipótesis de este libro, que señala que solamente podemos seguir a Jesús si realmente Él fue un ser humano como nosotros. Y porque nos devuelve justamente nuestra verdadera humanidad tan necesitada por el 'hombre' de hoy.

Y la idea es justamente acercar la figura de Jesús, porque Él estuvo cerca de la gente, como se afirma muy claramente en las escrituras, en la Epistola a los Hebreos, en el capítulo II, IV, luego en el capítulo XI de la Epistola a los Filipenses: «Jesús era igual en todo a nosotros».

Y realmente fue así, porque tuvo que aprender, tuvo que sufrir, pasar hambre, pasar necesidades, etcétera, como pasamos todos. La única excepción 
que se hace es que fue en todo humano «menos en el pecado». Pero en vez de ser un problema es algo que nos puede ayudar a comprender mejor y maduramente lo que es el pecado. La noción de pecado que tenemos es un poco infantil, se piensa que es la transgresión de una norma, de un mandamiento, pero la noción de pecado más profundo y muy cercano también a la Escritura y es de qué nos hace menos humanos.

$\mathrm{Y}$ en ese sentido Jesús no es menos humano que nosotros; todo lo opuesto: es más humano. En realidad Jesús es el paradigma de lo humano para el cristiano. El paradigma donde tiene que mirarse el hombre es en la figura de Jesús. Pero si la figura de Jesús la hacemos muy admirable, como se ha hecho en la catequesis, pero no imitable, es decir, no seguible, entonces, se va a la Iglesia, se reza, etcétera, pero en la vida cotidiana de las personas, en el trabajo, en la familia, y así en toda la vida, no se trasluce el Evangelio, no se trasluce el estilo de vida de Jesús.

Lo que se trata en mi libro es justamente esto, porque, como se dice en la introducción, el hombre es un ser en busca de su humanidad, el hombre es una gran pregunta. Y este es el énfasis de lo que buscamos en el libro; es que la gran pregunta, el gran enigma que es el ser humano para sí mismo se ilumine con la figura de Jesús, con el misterio de la figura de Jesús.

Debido a esto el libro se divide en dos partes concretas. La primera está referida a los diversos aspectos que hacen humano a Jesús. ¿Qué es lo que lo hace humano? En esta parte resalta la inteligencia de Jesús como búsqueda de la verdad, la libertad, la afectividad, la acción, en particular, estudiados desde la filosofía y antropología de lo humano; para preguntarnos después: «¿Y esto cómo lo vive Jesús?». A esta pregunta responde toda la segunda parte del libro: Jesús cómo vivió su ser realista, cómo practicó su libertad, como amó, etcétera; entonces, la idea es decir cómo Jesús nos puede enseñar a ser más humanos. Y 
al mismo tiempo descubrir en nosotros la humanidad de Jesús que realmente, como dice Karl Rahner: los cristianos a veces somos más monofisitas y docetas, puesto que lo que nos parece más importante y subrayamos es la divinidad de Jesús, pero la humanidad se tiene olvidada.

El misterio central de la salvación es la Encarnación, es un Dios que se despoja de su divinidad como dice la Epistola a los Filipenses, capítulo II: "Jesús se despojó de su divinidad para vivir y hacerse solidario de nuestra humanidad», y esto es lo extraordinario.

\section{LO QUE TRATA EL EVANGELIO ES CÓMO VIVIR LA VIDA MISMA}

¿Por qué es tan difícil en la vida práctica, en la vida ordinaria, en la vida común, ver la humanidad de Jesús? ¿Qué nos impide acercarnos a esta realidad de Jesús y que al mismo tiempo es de una crucial y vital importancia?

El problema es lo que suelo llamar «pecado religioso», y consiste en estar bien con Dios, practicar un tipo de religiosidad, de relación con Dios, pero con un Dios hecho a nuestra propia imagen, y donde los hechos de nuestra vida cotidiana están totalmente desconectados de esta especie de ritualismo. Entonces, cuando uno pregunta: «¿Tú eres cristiano?», «itú eres católico?». Las personas suelen responder de inmediato que sí. Pero cuando uno les pregunta el porqué, las respuestas son "porque voy a Misa los domingos», «bautizo a mis hijos», «me he casado por la Iglesia; y si insistimos con nuestras preguntas: «¿Y esto cómo lo vives en el trabajo?», «¿cómo practicas en tu empresa tu cristianismo?», la mayoría se quedan sorprendidos como diciendo que en estos lugares no tendría que intervenir el hecho de ser cristiano, pero justamente de esto trata la vida cristiana.

Por supuesto que son buenos los sacramentos, mas estos son una ayuda para vivir en cristiano no un valor aparte, pero, claro, es mucho más 
fácil el vivir de alguna manera vidas paralelas, y este hecho es realmente triste: por una parte la religiosidad y por otra la vida común. Y de lo que trata el Evangelio es cómo vivir la fe en todos los ámbitos de la realidad y no una separación o dualismo. El papa Juan Pablo II decía que uno de los grandes escándalos es la separación entre la fe y la vida, entre la fe y la cultura de la persona, y nos decía que una fe, un Evangelio, que no se hace cultura, es una fe «no plenamente acogida, no enteramente pensada, no fielmente vivida».

\section{JESÚS VENCIÓ TODO PREJUICIO POR SU INTELIGENCIA Y LIBERTAD}

Podria afirmar que en las aseveraciones tan provocadoras que usted hace mención se puede notar la exigencia de la capacidad humana correspondiente a su libertad, sin la cual sería imposible ver en Jesús su humanidad y direccionarla hacia este hecho

Sí, este es un caso concreto. Ha tocado el gran tema de la libertad, porque si ha existido un hombre libre, auténticamente libre, ha sido Jesús. Él se manifestaba libre de todo prejuicio. Para entender mejor la cuestión es necesario retomar, en este caso, dos aspectos de la humanidad de Jesús: su inteligencia y su libertad.

Jesús fue un hombre que en una sociedad llena de prejuicios machistas, moralistas y religiosos- se presentaba totalmente libre. Y capaz de ver al hombre en sí mismo y no ve en el otro si era judío o no judío, si lo era tanto de nacionalidad como de religión, o si era hombre o mujer.

Por eso, san Pablo puede decir después en la Epistola a los Gálatas que ya en Cristo no hay separación entre pagano y cristiano, entre hombre y mujer, y más bien que somos uno, porque Él venció todo esto por su inteligencia y libertad, supo vencer los prejuicios de su época, que incluso le costaron la vida. 
Esa libertad frente a todo, de no ver a la gente encuadrada por su clase social o su religión le permitía ver la condición del hombre, en cualquier hombre, sobre todo en los marginados, los pobres, los pecadores, los pequeños ante el mundo, esto es lo que ofrece el Evangelio y nos hace ver que Dios está de parte de la persona a la que se le despoja de su humanidad. Cuando se le despoja a alguien de dignidad humana, Jesús, sale en defensa de esta persona, del niño, del más débil; a veces, por ejemplo, la cercanía de Jesús con los niños uno lo ve como cosa simpática y es mucho más que eso, el niño era de los más marginados junto con la mujer.

Entonces, cuando Jesús dice que entrarán al Reino de los Cielos los que se parecen a los niños se refiere a aquellos a quienes se les ha despojado totalmente de sus derechos, lo mismo que la mujer, y Jesús los reivindica de manera absoluta; por eso dice que los últimos serán los primeros. El pedido de Jesús es un reclamo al valor y dignidad que tienen frente a Dios. El ser humano vale en sí mismo y no por su dinero, su poder o su religión, sino por ser humano simplemente y por eso también el título de mi libro: Ser Humano.

\section{LA HUMANIDAD DE JESÚS NOS REVELA LO QUE ES DIOS}

Hay una cita de Karl Rahner que nos impresionó al leer su libro y fue una de las grandes motivaciones para buscar esta entrevista, la cita dice así: "Que toda teología es eternamente antropología". ¿Nos podría explicar aun más la profundidad de esta cita tan interesante?

La cita de Karl Rahner dice algo más que la que menciona, él afirma que: «la antropología es una cristología deficiente que todavía no llega a su plenitud y la cristología es la antropología plenificada». Y es muy acertado. Porque ya a partir de Jesús a Dios no se le puede separar del hombre. 
Realmente de lo que trata el Evangelio, la Biblia entera, no es el misterio de Dios separado, sino siempre en relación con el Hombre y del hombre con Dios. Por eso al hombre no se le puede concebir sin su relación con el otro hombre.

Pero al hombre tampoco se le puede entender sin la relación con Dios. Al hombre se le entiende verdaderamente en su relación con Dios. Y eso se da justamente en la figura de Jesús, porque precisamente el misterio de Jesús trata de cómo Él es plena y totalmente hombre, ser humano, y al mismo tiempo totalmente y plenamente hijo de Dios; es decir, Dios. Y no a pesar, como sucede en un dualismo, sino que en su humanidad nos está revelando lo que es Dios. En la humanidad de Jesús es donde debemos ver la divinidad de Dios, no a parte de, sino en su humanidad.

¿Solo por la humanidad de Jesús se reconoce su divinidad, además de reconocer, también, lo divino en nosotros mismos?

Así es, la figura humana de Jesús nos permite descubrir en nosotros lo divino. Jesús vive, muere y resucita por nosotros. Esto es lo que señala la doctrina católica en el Nuevo Testamento, que por su humanidad nos está descubriendo nuestro propio misterio. La Epistola a los Colosenses dice que el misterio de nuestra vida está escondido con Cristo en Dios. Tampoco se trata, como afirmo siempre, de ver una figura puramente humana de Jesús; más bien se trata de percibir la trascendencia de nuestra humanidad porque estamos llamados todos a ser hijos de Dios. En Jesús, todos, todas somos hijos de Dios. Por eso es que la Epistola a los Romanos dice: «Jesús es el primogénito en medio de numerosos hermanos». Y eso es lo bello, descubrir que siendo humanos, sin dejar de ser humanos, podemos ser cristianos. No me tengo que deshumanizar o buscar la plenitud fuera de lo humano. Lo que debo hacer es buscar mi identidad cristiana y humana en lo humano, 
porque ahí la encontró Jesús, viviendo su humanidad hasta el fondo. Que es lo que nos dice el famoso himno a los Filipenses: «Se despojó de sí mismo y se hizo un hombre cualquiera». Jesús no tuvo ningún título, ni siquiera fue sumo sacerdote, fue un hombre cualquiera.

\section{¿Sería justo afirmar que nosotros también, como Iglesia, no hemos ayudado y hemos deshumanizado a Jesús?}

Quizás, es un problema de la religión, separamos lo humano de lo divino. Entonces, se pone lo religioso separado de nuestra humanidad. Pero tenemos que volver al misterio de la Encarnación, hay que renacer en la Iglesia. Ya que al hombre solo lo descubrimos en el hombre y a través del hombre, esto es fundamental. Porque si no nos fabricamos un Dios a nuestra manera, justamente lo que está tan criticado en la Biblia, el hacernos ídolos (imágenes falsas de Dios). Y la manera de no llegar a esta situación es mirando a Jesús.

Cuando nosotros contrastamos lo que pensamos de Dios con lo que vemos de Dios en Jesús es cuando realmente creemos en el Dios cristiano. Si no hiciéramos esto inmediatamente nos haríamos una imagen del Dios que quisiéramos ser. Queremos tener dinero, nos hacemos un Dios que lo tiene todo, que lo posee todo, que lo puede todo, que lo sabe todo; ese es un ídolo. En cambio, en Jesús encontramos el contraste de Dios en un hombre que aprende, que es humilde, que es un hombre pobre, ahí encontramos a Dios; en aquello que parece lo denigrable en nuestro mundo que glorifica el poder, riquezas, las apariencias, etcétera, vemos un Jesús y a Dios en Él, que fue débil y pobre; y eso no es una casualidad. Es una ruptura de nuestros esquemas y por eso también difícil de aceptar.

Usted lo ha indicado: ver a Dios en Jesús es difícil porque no se ve en el Evangelio la figura de Jesús que es el reverso de todo lo que somos en nuestra sociedad. Por eso solo se vuelve una figura admirable, como dijimos, porque es 
más cómodo; como confirman mis alumnos en la Universidad cuando afirman que lo que les digo sobre la persona de Jesús es idealista y no realizable, que es algo utópico, ya que no se puede vivir, pero les señalo que es la forma de ser más humana que pueda existir en el mundo, y que lo que nos plantea Jesús es plenamente posible para los seres humanos porque Jesús lo vivió siendo humano, en el dolor y el sufrimiento de por medio. Es como realmente se aprende a decir que sí se puede vivir el Evangelio.

\section{EL RECLAMO DEL EVANGELIO ES EL SER FIEL AL 'YO PROFUNDO' DE CADA UNO}

En esta posibilidad de vivir el Evangelio, como indica, se nota un peligro que ha estado presente en toda la tradición de la Iglesia, el de ser solamente unos repetidores, o en el hecho de ser una copia de Jesús perdiendo nuestra original libertad dado un contexto situacional que nos haya tocado vivir; ¿es esta experiencia la que nos aleja de vivir según la figura humana de Jesús?

Lo que dice el Evangelio es que no debemos ser una copia de Jesús. Los buenos teólogos no hablan de la imitación de Jesús, sino del seguimiento de Jesús; que seguimos un estilo de vida y no copiamos. Primero porque nos separan veinte siglos y Jesús tenía una personalidad determinada, nosotros tenemos otra personalidad y vivimos en otra época; entonces, lo que haríamos sería una caricatura de Jesús al querer copiarlo. Y lo que plantea el Evangelio no es copia, sino seguimiento y un seguimiento creativo. De tratar de encarnar el Evangelio como Jesús lo encarnó en su época. Nosotros vivimos ahora nuestra propia experiencia de Dios. Eso que pedía a la Iglesia Juan XXIII, que abriéramos las puertas de la Iglesia al mundo, porque sino al hombre de este siglo no le decimos nada. En tal caso sería algo bonito, admirable pero no nos dice nada sobre cómo tenemos que vivir en conflictos sociales, en nuestros propios problemas, en 
nuestras dificultades, etcétera. $Y$ así como Jesús supo enfrentar las dificultades de su época, nosotros en su seguimiento, no en su imitación, tenemos que enfrentar los problemas de nuestra época con ese criterio.

Otro peligro que se observa es seguir a Jesús disculpando la forma de ser que presentamos y que puede ir en contra de la misma figura de Jesús, pero que pasamos por alto porque afirmamos que asi es nuestra personalidad, o nuestros afectos, mucho más, afirmamos que asi es nuestra humanidad, ¿es esto cierto?

Primero aclaremos que en Jesús no hay un modelo de ser humano. No pide que el ser humano debería de ser de tal forma sino que el reclamo del Evangelio es el ser fiel al «yo profundo» de cada uno; porque si Dios nos ha hecho como somos no nos pide ser de otra manera. Lo que quiere Dios es que seamos como Él nos ha creado, otra cosa es que si nosotros tergiversamos nuestra verdadera identidad de ser imagen y semejanza de Dios, de lo cual se cuenta en el libro del Génesis.

Sobre el tema de las pasiones, la afectividad es sumamente sana en el hombre ya que generalmente el centro del Evangelio es el amor. Hay un teólogo judío, de religión judía, Abraham Heschel que afirma que se podría resumir lo que es Dios como el apasionado por el hombre, en el sentido del amor pleno al hombre. Lo que encontramos en Jesús es un hombre equilibrado en sus pasiones, en su amor. A Jesús se le conmueven las entrañas al ver el dolor de las personas, lo dice el Evangelio, no es indiferente ante el dolor. Pero al mismo tiempo no es un hombre que se deja llevar por lo puramente sentimental.

El amor del que habla el Evangelio es la búsqueda del bien de la otra persona y no se busca el bien de la otra persona cuando uno se deja llevar por la pasión. Se dice que hay pasiones que matan, los celos por ejemplo, Jesús nunca vivió una pasión así, siempre su amor busca el bien de la otra persona. Y esto nos puede ayudar más a comprender el sentido del amor. Pues nos libera de un amor 
puramente romántico, sentimental y nos lleva a un querer realmente eficaz en la búsqueda del bien real del ser humano.

\section{EL AMOR NOS PERMITE ACERCARNOS AL QUE ES DIFERENTE A NOSOTROS}

Cerrando esta entrevista y el agradecimiento profundo por su generosidad, usted al hacer mención a lo que llama 'yo profundo' plantea una salida al problema que existe respecto del diálogo con otras religiones y, por qué no, incluso con nuestros prójimos de la religión a la que pertenecemos. ¿Cómo iniciar este diálogo mediante este 'yo profundo' al que hace alusión?

Dios no es un concepto, una definición. Lo que se jugó en la vida de Jesús fue la libertad, el amor, la verdad, la justicia. Y ahí donde haya verdad, amor, libertad, justicia, ahí está Dios, y donde no se dan no está Dios así sea algo religioso. Lo que dice San Juan: «El que ama ha conocido a Dios y el que no ama no ha conocido a Dios». Y Jesús dice: «no el que dice Señor, Señor entrará en el Reino de mi Padre sino el que hace la voluntad de mi Padre».

En el Perú, donde el 90\% se dicen cristianos y católicos, es un escándalo que existan problemas graves de injusticia y pobreza. Cómo en un país que se dice cristiano existe falta de amor por los demás. Aquí reside lo que llamo el escándalo de la separación entre la fe y la vida. Seguir a Jesús humano nos revela nuestra divinidad, como afirmamos líneas atrás, pero es el amor lo que nos permite justamente acercarnos al otro, al que es diferente a nosotros, al que piensa distinto, al que no nos agrada. Espero que mi pequeña obra sirva para despertar este amor en el seguimiento de la humanidad de Jesús encarnada en nuestras vidas. 